\title{
Network Finance-Financial Management Information in E Times
}

\author{
Hui ping Huang ${ }^{1, a}$ and Hui min Huang ${ }^{2, b}$ \\ ${ }^{1}$ Zao Zhuang College, Zao Zhuang, Shan dong Province, China \\ ${ }^{2}$ Bing Tuan College, Wu Jia Qu, Xin Jiang, China
}

Keywords: network finance; financial management; e times; safety issues.

\begin{abstract}
Our purpose in this report is to study the network finance. As a new way of financial management of e era, network finance has the following characteristics: financial management space to expand, financial management efficiency can be improved and synergy development of network finance between the various departments. Extensiveness of network finance, which performs: promotion of enterprise group management; popular in e-commerce; acclaimed in the mobile office; popularity of the page data; widely used of online management. Network financial management problems are: virtualization accounting entity; the financial problems of professional and technical personnel; safety issues; standardization of financial data interface of network. We propose the following countermeasures: upgrade financial software; paying attention to the training of technical personnel; collaborative use of enterprise management and financial management; strong security measures. Companies want to dominate in today's fierce market competition; they must establish a sound internal network financial system of their own.
\end{abstract}

\section{Introduction}

Relying on the growing popularity of the Internet and e-commerce, enterprise management model will change dramatically. Online trading and online services will become an increasingly important marketing content. Compared with traditional financial management, financial management to expand the network management, speeds up financial data for real-time financial processing, reduces the cost of financial management and improves the efficiency of financial management. With the advent of high-tech information age, global information processing networks will become an inevitable trend; e-commerce will become mainstreams. As an important part of e-commerce, online financial information system will change; the network will become the inevitable trend of development of financial management. "Network financing" can have the following definition: the network of financial software it uses to focus on the purpose of e-commerce, using the Internet to help businesses achieve financial and business collaboration, remote reporting, reimbursement, and to form an online financial network financial management information system [1].

\section{Development of Network Finance}

\subsection{Network Finance Produce}

The so-called financial system is to replace the network in a network environment, which is a Web-based technology, integrated enterprise e-commerce software for the financial management accounting and financial management system objectives and its various functions. Network Finance is financial activities connected with electronic information technology and network. It enables real-time Internet utilization fund accounting and auditing, dynamic reports in the network environment on the Internet, and to achieve synergies through the financial and business, financial and operational efficiency of the settlement process integration capabilities. Network Finance also formed inside and outside the enterprise customer-centric, online supply chain collaboration, dynamic management of suppliers, companies can fully grasp the source, reduces business costs. Online customer relationship management, will help enterprises to form a customer-centric philosophy, the establishment of an interactive dynamic customer profiles, online transfer, Internet marketing, customer relationship management (CRM), e-commerce services [2]. In the concept of network finance, corporate financial management is not only the internal financial management; financial 
management, can also be extended to the outer periphery of enterprises and companies to provide enterprise management capabilities greatly increased. Over time, after the past financial management feedback, companies can’t develop towards dynamic management of enterprise development to real-time monitoring, financial management from static monitoring. This will ensure timely detection of problems, the economic operation of the process; can also provide accurate and timely data for decision-making department. Environmental changes in time, so change the financial network financial management model; this will greatly enhance the management level and management efficiency.

\subsection{Inevitability of Network Finance Development}

The rapid development of the Internet economy and the emergence of electronic commerce, ensure maximum reflection and accounting control functions. The Internet has made news; e-commerce business has been rapid development. To address this challenge, a number of large enterprises establish their knowledge, to achieve the exchange and sharing of information on the website. Many companies rely on strong technical power of the Internet to build their own internal financial management information systems; e-commerce has become the main way to survive and trade in the Internet age [3]. Compared with the traditional manual processing methods, the network of financial accounting staff reduce labor intensity and improve the efficiency of culture, and promote the upgrading and billing functions. But it is still in a single operation or a major e-commerce business model age of the Internet and local area network (LAN) is inefficient. Financial management under the network environment need to address the following questions: First, electronic document processing and electronic currency clearing account for the development of the network; second, remote operation, information sharing. This greatly accelerated the capital and financial accounting, which is widely used in Internet business. Paperless accounting and network management are more complex. Online financial system began to take shape. Financial Network System network technology, there is a natural outgrowth of the development of its inevitability of environmental and technical conditions.

\section{Features and Extension of Network Finance}

\subsection{Features of Network Finance}

\subsubsection{Financial Management space to expand}

In a network environment, from the paper carrier data to magnetic media or optical carrier medium, a web page, all of the physical distance becomes the mouse away. Financial management capability in different regions may be extended to any node; accounting information transmission distance is no longer subject to any restrictions. Expansion of space, so that the development trend of financial management, from centralized to decentralized, from the inside toward the outside. Enterprise groups use the Internet for remote data processing, remote reporting, remote reimbursement, remote auditing and financial supervision audit remote branches; it can be very convenient remote control and inventory, sales management, remote monitoring and other services. Each branch employees, as well as through a network of data processing and financial resources, including centralized accounting accounts, accounting, report generation and accumulation of centralized management to achieve. It can focus on some of the financial data, all for centralized deployment within the Group funds to improve the comprehensive competitiveness of enterprises. Age of the Internet, more business depends on customers, suppliers, and changes in industrial economy, regional economy and global economy [4]. Online virtual enterprise organization and it will be directly related to the survival and development of resource flows is a common form. Therefore, the network will become more and more financial activities. In addition to online remote processing and centralized management, online shopping and on-line support; from online sales online billing, urges online account, online tax and customs; from online banking online services; from regulatory and financial information on the Internet to support online survey; from online banking, insurance, securities investment and overseas sales network on the Internet, which will become a tapestry network financing. Integration of online 
financial information can assure through the internal financial information "islands." to collect directly customers, suppliers, government departments and other relevant departments. Especially in the past to rely on a local area network and other stand-alone or in a small number of personal financial decision-making patterns on the network environment can be a joint decision by the relevant personnel interactive features of distribution network around the world. This scalable financial space, from decentralized to centralized, from the company's headquarters across the enterprise, toward the outside from within the enterprise.

3.1.2 Financial management efficiency can be improved:

Financial network systems, not only broke the concept of space, but also through the time constraints, broken. Later calculated from the static calculation-intensive dynamic accounting has greatly enriched the accounting information to improve accounting information value. It can easily produce a variety of dynamic financial statements to reflect the business and financial condition, financial reports. It enables enterprise financial management mode from static to dynamic and greatly expand significantly the quality of financial management. Desktop financial management model, mainly the information carrier sheet data and keyboard data, paperless financial networks and financial information, so that the data is converted into a simple web page, the user can be extracted at any time dependent. It also provides $7 * 24$-hour convenience services, financial reporting of listed companies more and more information at any time, open the entry of investors or shareholders in any direction, which greatly improved the timeliness of information. Electronic money is the foundation, construction funds of e-commerce, which is characterized not by check, money order, cash settlement bill important carrier network, but by the automatic electronic transmission on the network. The emergence of electronic money, not only greatly improve settlement efficiency, accelerate cash flow, reduce the cost of capital, but also that the electronic money will play a leading fund settlement areas. In the form of office, as well as Internet-based online office, remote office, distributed offices and mobile office might replace the current office. As long as the computer connected to the Internet, whether at work, at home or in almost all outside work through the computer can operate on the Internet. Real "big business shrink, complex organization becomes simple and clear," not only reduces operating costs, and more importantly improve work efficiency. With the financial, business and personal finance online users can not directly buy appropriate accounting and financial management services, network services expenditure corresponding amount under. Now, the financial management of SMEs online financial management has been accepted by many businesses, and in further planning and implementation.

3.1.3 Collaborative development of the network between the various departments of finance

In the modern business model, financial software application sector is gradually strengthened. Financial and other business information between each other will connect to each other gradually, share, and achieve coordinated management, operations, procurement, finance department development. Online financial system has been widely used in the enterprise. With different departments to interact and share enterprise information access, change the backward status quo. Financial and business is symmetrical, financial resources and operational coordination and synchronization in favor of the allocation of resources to optimize the configuration [5]. This synergy of business, including the business sector, such as online business purchases, online payment online sales and finance departments, online billing service Synergy cooperation; and supply chain collaboration, such as online, the Ministry of Finance, online account for online services providers, online sales coordination; coordinate with all relevant sectors of society, such as online banking, online insurance, online reporting, online reporting and so on. Whether it is inside or outside the company's business, once confirmed will be credited to the appropriate server, immediately sent to the financial information and real-time business information system detects automatically generated, reflecting the various dynamic business reports and financial information. Annual report, quarterly, monthly and daily dynamically generated, contrary to the assumptions of the theory of "accounting period", although the responsibility, but the development of financial accounting still something dynamic to reflect and monitor later. Users of financial information may at any time to understand and 
grasp the business and financial condition. Enterprise managers to provide real-time financial information to make decisions, accuracy and timeliness; risk control will be apparent. In short, the financial services network, reduce management costs, improve efficiency, greatly enhance the company's cohesion and competitiveness, consistent with and promote the development of enterprises. This is a major step forward in financial management.

\subsection{Breadth of Network Finance}

Traditional financial applications are mainly used in business; it is an objective reflection of corporate finance activities. Through the network of financial range of applications, mainly in the following aspects:

\subsubsection{Enterprise Group operating propulsion}

Remote reporting, remote reimbursement, financial data, such as remote monitoring and remote audit, you can easily control and monitor remote inventory, sales management, and other services. Branch employees at the same time through the network data processing and financial resources, including centralized accounting accounts, accounting, report generation and aggregated centrally managed to achieve and strengthen the governing units subsidiaries of financial management, centralized deployment of all funds enterprises to enhance the competitiveness of enterprises.

\subsubsection{Top E-commerce}

It is essential to implement online banking electronic money. Online financial environment is one of a series of network system manufacturers, suppliers, distributors, users and BIS countries. There are no direct financial transactions, once the bank's capital will be the timeliness of the information, and then communicate with the business in the form of information, in order to achieve its function as money.

\subsubsection{In the acclaimed mobile office}

Financial networks are changing the way accounting personnel; financial operations can be achieved dynamic process. Network Finance full uses of the Internet, anytime, anywhere with the company timely communication. It is the concept of financial management, or even travel or business process can also process a new office in remote areas.

\subsubsection{Page data Popularity}

Finance network has greatly changed the provision of financial information. From the traditional paper-based text-based data to computer-based data current page, regardless of company size, its financial management will take the form of a page. "Big companies will become small and small enterprises will become big." Each business will be in a fairer competitive environment to survive. With the provision of financial information to distinguish the traditional way, the network data link function allows greatly improved the timeliness of the information, a significant increase in visual page, limiting the time and space no longer.

\subsubsection{Widely used in network management}

Using dynamic accounting information, business activities can be timely deployment of corporate treasurers and financial arrangements. Compare real-time online feedback management is mainly used for on-line content. Use the online reports, internal and external information needs can be dynamic real-time access to financial and non-financial information. Use the online feedback, dynamic tracking every change, and then give the necessary disclosures. Real-time analysis is dependent on the information network environment accounting personnel database, access to relevant financial indicators and other dynamic companies in the industry, and then analyzed and compared to predict future business trends. And traditional management model, the new model of network management, can better help companies in the Internet economy's competitive advantage. 


\section{Problems and Countermeasures Financial Management of Network}

\subsection{Issues of Network Financial}

\subsubsection{Virtualization accounting entity}

Accounting entity refers to the object of accounting services. In the traditional financial management, accounting entity is an entity unit, and physical form. In the e-commerce environment, the nature of the spatial characteristics of management accounting entity has changed. With the Internet, you can achieve remote object business services, information flow; traffic in the network environment can greatly simplify many intermediate links. Online banking, electronic documents, each electronic transaction process become electronic. Transaction process becomes virtualized, forming a network of e-commerce environment. Accounting entity virtualization is an important issue facing the financial network. Because at this stage, the main accounting network virtualization is also relatively obscure state enterprises will be the subject of virtual network economy and facing the need to identify, to determine its virtual network financial management.

\subsubsection{Financial professional and technical personnel}

The financial network system is an electronic network and financial management of the combined product. Network technology and financial management are two different branches of science; it is not only for professionals skilled in computer network technology needs, but also the need for financial management, financial and business skills equivalent knowledge.

\subsubsection{Security issues}

Open network is double-edged sword, although the financial system through the digital computing, the advantages of electronic document applications is due to the characteristics of open network technology. But from another perspective, it is due to the open nature of the network, to make financial information more threats [6].

\subsubsection{Network interface standardization of financial data}

The financial network system applications and a variety of internal management systems currently multilateral relations, and financial networks, rather than external social sectors, such as banking, taxation, insurance, customs and other data that may occur exchange. Thus, the data network is facing the financial system interface standardization issues. Usually there are many, but it lacks a standard, unified data input and output interfaces at this stage of the market's network of financial software-related. Not freely exchange data between software and therefore adversely affect the financial network system application software, financial networking features.

\subsection{Measures Development of Financial Management.}

\subsubsection{Upgrade Financial Software:}

In the 21st century, with the escalation of computer hardware and software, graphics development, and jointly promote the application of graphical management of financial software into the era. From simple digital reports, upgrade to graphical interactive financial statements, allowing users to more vivid and intuitive understanding of corporate financial management information.

\subsubsection{Attach importance to training of technical personnel}

Compared with the traditional model, accounting for generating mode information and financial management mechanism of network environment has changed radically. In the environment, finance, corporate accounting personnel action, such a change is likely these changes to some extent. Many enterprises lack sufficient technical staff to handle the development of financial problems encountered in the network. In fact, the technical bottleneck of talent shortage has affected the development of enterprise groups.

\subsubsection{Use of business and financial management of cooperation}

We should also recognize that the network of the financial system is an integral part of the enterprise management information system. It is proposed that only the financial concept of "Financial Network", but stressed that the technical aspects of the network is not enough. Only financial network effectively integrated into the enterprise resource planning system, as well as venture capital, technological innovation, human resource development and a series of business management, financial management used in conjunction, can play the role of its head. 


\subsubsection{Strong security measures}

Financial network system, so that the original single computerized accounting information system has become an open area. Many similar features accounting, the need for data confidentiality. Therefore, the security issue has become very popular with concern the financial system users on the network.

\section{Conclusion}

With the advent of the Internet age, the network of financial development has become an irreversible trend. The company hopes to use in today's highly competitive market; we must establish and improve the financial system's own internal network, to expand their influence and visibility.

Financial network system, as a new model of financial management, not only can achieve all financial functions on the desktop, as well as more traditional financial management innovation.

Enterprises can integrate use of modern electronic means of information, oversee the company's financial resources, to strengthen the supervision of the financial sector lower, reduce operating costs and improve efficiency.

Networking technology will be the key to remain competitive; it is no longer just a common enterprise business tool, but implements the necessary financial management and cutting-edge network enterprise value growth.

\section{References}

[1]. Ruijun Zhang, "Financial management of E era,” Beijing: People's University Press, 2004, pp.68-73.(In Chinese)

[2]. Min Xu, "Network Finance - The new financial management concepts of e Times,” Public, 2005, pp.22-23. (In Chinese)

[3]. Xiaona Wang, “Electronic Commerce Network Financial Management,” Dalian: Dalian Maritime University, 2006, pp.15-16.(In Chinese)

[4]. Tao Yang and Junwei Sun, “Transition of the Enterprise Financial Management Mode,” Modern business, 2011 , pp.31-32.(In Chinese)

[5]. Wei Jin, "On the Application of Network Finance," Chinese Chief Accountant, 2004, pp.27-28.(In Chinese)

[6]. Guoqiang Zhang, Yan Ma and Zhihui Xu, "On functions and safety of the network finance," Business Economics, 2005, pp.41-42.(In Chinese) 